\title{
Development Of An Integrated Operating Framework For Strategy Execution In Gauteng Municipalities In South Africa
}

J. H. Leibbrandt, North-West University, South Africa C. J. Botha, North-West University, South Africa

\begin{abstract}
The establishment of a new democracy has created high expectations amongst all the different communities of South Africa. The demand for basic essential services by the previously disadvantaged communities has increased drastically, whilst at the same time, communities from developed areas are expecting and demanding an acceptable level of maintenance and services in their respective areas.
\end{abstract}

Municipalities are in serious distress with regular service delivery protests, huge service delivery and infrastructure backlog challenges (e.g., electricity, roads, housing, water, and sanitation), poor financial management and the inability to execute approved strategies, plans, and programs.

This article focused on the municipalities in the Gauteng Province of South Africa and the main objective was to answer the survey question: "What prevents Gauteng municipalities to successfully execute its strategies and what can be done to address the situation?"

The research objectives were firstly, to review the literature and determine the key enablers required for successful strategy execution; secondly, to analyze the findings of the empirical research and to make recommendations towards the improvement of strategy execution within Gauteng municipalities. The third and final objective was to develop an integrated operating framework for strategy execution in Gauteng municipalities.

The article concluded by making recommendations towards the improvement of strategy execution within municipalities and developing an integrated operating framework for strategy execution. The results of the literature review as well as the empirical research were taken into account during the development of the integrated operating framework.

Keywords: Strategy; Execution; Planning; Integrated; Framework; Management; Leadership

\section{INTRODUCTION}

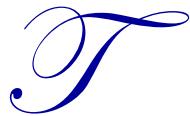

he Constitution of South Africa (SA, 1996) introduced the concept of cooperative government, in terms of which tiers of government were substituted by spheres of government. The Constitution (SA, 1996) established a distinct developmental role for local government and in section 152 established the objects for local government as:

- $\quad$ to provide democratic and accountable government for local communities;

- $\quad$ to ensure the provision of services to communities in a sustainable manner;

- to promote social and economic development;

- $\quad$ to promote a safe and healthy environment; and

- to encourage the involvement of communities and community organizations in the matters of local government. 

follows:

The Constitution (SA, 1996) in Section 153 determined the developmental duties of local government as

- $\quad$ to structure and manage its administration and budgeting and planning processes to give priority to the basic needs of the community and to promote the social and economic development of the community; and - $\quad$ to participate in national and provincial development programs.

The promulgation of the Local Government Municipal Structures Act (SA, 1998b) and the Local Government Municipal Systems Act (SA, 2000a) provide the legal framework for integrated development planning, performance management, leadership, and the required structures.

The Structures Act (SA, 1998b) mainly provides for the disestablishment of former racially based independent municipalities and the establishment of structures in the form of:

- metropolitan, district, and local municipalities;

- $\quad$ an executive mayoral system;

- a mayoral committee; and

- $\quad$ ward committees.

Section 56 of the Structures Act (SA, 1998b) stipulates the functions and powers of executive mayors which, inter alia, include the following:

- $\quad$ to identify the needs of the municipality;

- $\quad$ to develop strategies to address priority needs;

- $\quad$ to establish performance criteria;

- $\quad$ to monitor the management of the municipality; and

- $\quad$ to oversee the provision of services to communities.

Section 25 of the Systems Act (SA, 2000a) prescribes and stipulates the minimum requirements for developing an Integrated Development Plan (IDP). Each municipality must, within a prescribed period after the start of its elected term, adopt a single, inclusive strategic plan for the development of the municipality which:

- links, integrates, and coordinates plans and takes into account proposals for the development of the municipality;

- $\quad$ aligns the resources and capacity of the municipality with the execution of the plan;

- $\quad$ forms the policy framework and general basis on which annual budgets must be based;

- $\quad$ complies with the provisions; and

- $\quad$ is compatible with national and provincial development plans and planning requirements binding on the municipality in terms of legislation.

With regards to Performance Management, the Systems Act (SA, 2000a) in terms of Section 38 prescribes that each municipality must establish a performance management system that:

- $\quad$ commensurate with its resources;

- $\quad$ is best suited to its circumstances;

- $\quad$ is in line with the priorities, objectives, indicators and targets contained in its integrated development plan;

- promotes a culture of performance management among its political structures, political office bearers, and councilors and in its administration; and

- $\quad$ administers its affairs in an economical, effective, efficient and accountable manner.

The preceding pieces of legislation provide an enabling legal framework and clearly indicate the developmental role and primary objectives and developmental duties of a municipality. It furthermore, stipulates the minimum requirements for developing an Integrated Development Plan (IDP) and the establishment of a performance management system. 
However, despite enabling legislation, the Overview Report (SA, 2009a, p. 4) confirmed the inability of municipalities to execute approved strategies, IDPs and Programs. The Overview Report (SA, 2009a, p. 5) pointed out the need to "identify the mismatch between intent and practice" as well as the need to assess "the reality of poor municipal performance" within the local government sector.

The purpose of this research is to establish what are the reasons and contributing factors causing municipalities to fail in executing their approved strategies.

\section{METHODOLOGY}

\section{Literature Review}

The purpose of the literature review is to explain "Strategy Execution" as a concept and to establish a normative model against which the research results can be benchmarked. As secondary research the literature review forms the basis and background for the primary research.

\section{Research Design for the Survey}

After careful consideration of the various research approaches, it was decided to utilise quantitative research, which is exploratory in nature, as the primary data collection method for the purpose of this survey.

\section{Structured Questionnaire}

For the purpose of this study a quantitative research approach utilizing a structured questionnaire with closed questions was chosen as the preferred tool and method to answer the research question and to arrive at the expected results.

The structured questionnaire was drafted from the concepts, classifications and different execution frameworks that were discussed in the literature review. The purpose of the questionnaire was to establish the municipality's current state and ability to execute strategies. "Strategy Execution" in this questionnaire refers to the execution or implementation of strategies, plans, and policies of the municipality. The questionnaire was handed out at the survey sessions. The participants were willing to be honest as their anonymity was assured (Salkind, 2007, p. 138). The questionnaire posed the questions (statements) on a four-point Likert Scale with a fifth "Don't Know" option. The participants had to consider the following options in responding to each statement:

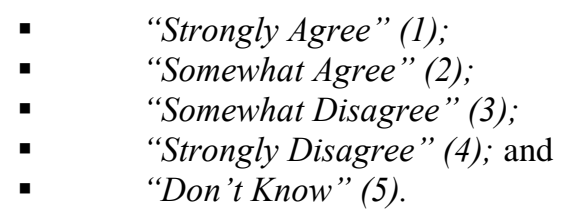

Based on the literature and strategy execution framework review, the following enablers were identified to be researched in order to understand the state of strategy execution in the twelve (12) Gauteng municipalities:

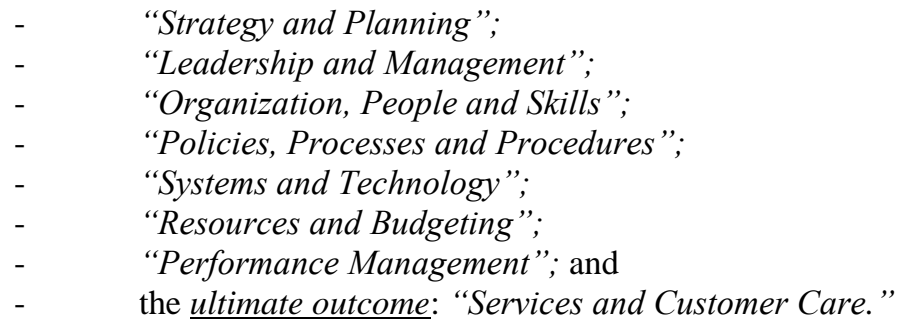


A factor analysis was used to identify the structure and factors of each enabler and through this process the structural validity of the survey was also determined (Pietersen \& Maree, 2007, p. 219). According to Pietersen and Maree (2007, p. 219) the purpose of a factor analysis is to determine which statements (items) belong together due to the fact that it measures the same factor.

\section{Target Population}

The population of this study comprised of all the senior and middle managers in the Metropolitan, District and Local Municipalities and within the Gauteng Province:

The targeted population consisted of those senior and middle managers responsible for strategy formulation and planning, execution, and service delivery as well as two union leaders (shop stewards) representing the two largest unions per municipality. The target population comprised of 351 targeted participants.

Sampling

To ensure sample adequacy it was decided to use the entire target population as the study sample. All Metropolitan, District, and Local Municipalities and the targeted role players within the Gauteng Province formed part of the survey.

To protect the identity of the participants the questionnaires was completed anonymously and placed in a sealed and unmarked envelope. A sealed box per municipality (clearly marked) was used to place the completed questionnaires into.

The target population consisted of 412 people. A total of 379 completed questionnaires were collected. The 379 respondents who responded formed the study population.

\section{STRATEGY EXECUTION}

Strategy execution is defined by various authors as follows:

- $\quad$ the actions required converting the strategy into success (De Flander, 2010, p. 15);

- the successful execution of strategic decisions (Flood et al., 2000, p. 2);

- all the processes and outcomes which follows a strategic decision and when the decision is put into practice (Miller et al., 2004, p. 203);

- a systematic process of continuously following through and allocating accountability (Bossidy et al., 2002, p. 22);

- the realization of intentions (MacLennan, 2001, p. 11);

- the sum of the activities and choices required to execute the strategy successfully (Wheelen \& Hunger, 2004, p. 192);

- the action that moves the organization along its choice of route towards its goal, the fulfillment of its mission, the achievement of its vision and the realization of intentions (Tony Eccles in MacLennan, 2011, p. 11); and

- all the processes and outcomes which follow a strategic decision once authorization has been obtained to put the decision into practice (Miller et al., 2004, p. 201).

\section{Strategy Formulation}

Many senior managers in positions of leadership seem to believe that a well formulated strategy which is well communicated to the organization equals implementation. In reality many carefully drafted strategies are simply never fully and successfully implemented, due to the fact that many organizations find it difficult to bridge the "knowing-doing" gap. (Beer \& Eisenstat, 2000, p. 29; Raps, 2004, p. 53). 
Strategy formulation and the execution thereof are viewed by organizations as separate parts of the strategic management process and are at the root of many failed strategies (Nielson, 2008, p. 1; Schaap, 2006, p. 23; Hrebiniak, 2008, p. 1; Davenport, 2007, p. 1). Most strategies are formulated by the top team and are supposed to be executed by another team (Spinosa, 2008, p. 27).

Strategy formulation and execution are interdependent and forms part and parcel of the overall planning and execution process. The transferring of knowledge and commitment to the execution process will be sacrificed if the managers responsible for execution are not involved in the planning process (Hrebiniak, 2008, p. 1).

MacLennan (2011, p. 27) points out that the potential value of strategic planning is lost due to strategies that realistically are not actionable and that some leaders are reluctant to spend time and energy on execution because they view it as messy and something that junior employees should deal with. Hanley $(2007$, p. 18) points out that a complex strategy reduces the chances for successful execution and those projects and programs that can easily be supported by the existing staff and infrastructure should be high priorities for execution.

Strategy execution is a discipline which forms part of strategy formulation; it is a core function of the business leader and must form a core component of an organization's value system and business culture. No strategy should be planned without taking into account the organization's ability to execute it (Bossidy et al., 2002, p. 21).

Hanley (2007, p. 17) points out that senior management frequently argue that the strategic plan was conceptually sound but suffered from a lack of 'follow-through'. Execution efforts are often derailed by a lack of management commitment, lack of resources, or an ineffective project management structure. Executing strategy, more often than not, receives less attention than strategy formulation (MacLennan, 2011, p. 25).

From the aforementioned literature review it is clear that the strategy forms the main input into the execution process of any organization and that the strategy execution process starts with the development of a credible, simplified, and executable plan. The strategy must be preferably be developed by the same team that would be tasked with the execution thereof. It is important that the strategy gets converted in a plan that deals with the basic details of "how," "who," "when," "where," and "why."

\section{Leadership and Management}

A key function of management is to recruit and develop talented employees fully aligned with the organization's strategy, setting the course, and empowering them as required to carry out their functions. The vision and priorities should be linked to individual and team goals. This will lead to an aligned and motivated organization, which will be effective in execution (Brenes, 2008, p. 592).

Culture drives the way the organization implement its strategy. The leader's role is to ensure that the organizational culture enables the execution of the strategy and if it does not, an aligned culture must be build. Once leaders have defined the strategy, they must set their people up for success by ensuring that the culture supports the required behaviours and actions. This is achieved by reviewing current social norms and rituals. Leaders must examine the day-to-day activities of the organization to ensure it drives strategy execution (Hrebiniak, 2005, p. 25; Speculand, 2009, pp. 72-73; Coughlin, 2005, p. 1; Heide et al., 2002, p. 219; Kumar, 2010, p. 323; Bossidy et al., 2002, p. 30).

Pearce and Robinson (2001, p. 326) argue that leaders must lead on two fronts: (1) they must embrace change by clarify the strategic direction, build the organization, and shape the culture to fit the challenges and opportunities offered by change; and (2) they must provide the management skill to cope with the implications of constant change.

Middle managers play a crucial role in the successful execution of an organization's strategy and should be consulted when strategies and plans are formulated. Without the support and buy-in of the middle management the organization will battle to execute the strategy successfully. It is important that middle managers "are treated like VIPs" and acknowledged when they contribute towards the success of the organization (Artunes et al., 2010, pp. 116 $-120)$. 
Speculand (2009, pp. 10-11) is of the view that leaders should focus on five (5) roles as to ensure successful execution of the strategy: (1) focus on both crafting and implementing strategy; (2) create the right conditions; (3) identify what needs to be done; (4) adapt and amend the strategy; and (5) create an implementation plan.

Schaap (2006, p. 16) stated that in a recent study more than $40 \%$ of senior managers and $90 \%$ of the employees indicated that they do not have a clear understanding of their organization's strategy. Poor communication is one of the main reasons why execution has failed in organizations. Strategy is normally designed at the top, but executed from the bottom.

A strategy that is clear and effectively communicated will not add significant value unless everybody in the organization understand how their actions are strategically aligned and contribute to the strategy execution process. In many cases, strategies are defined at the top of an organization, with no clear cascading of responsibilities for the tactical specifics necessary to achieve results. High-level strategies must be broken down into specific subobjectives, which can be owned and executed at every level (Hitachi, 2009, p. 4).

When communicating the strategy and its execution, leaders must be visible throughout the organization and find as many ways as possible to repeat the core messages. When leaders become the voice of the strategy, it demonstrates to the entire organization not only the importance of the strategy but also the focus and commitment of the leadership on its implementation (Speculand, 2009, pp. 42-43; Heide et al., 2002, p. 218).

Even when the strategy is clearly formulated and defined, it is not always effectively communicated. The study by Jooste and Fourie (2009, p. 65) found that a lack of understanding and poor communication of the strategy to the workforce are the most important barriers to effective execution. The creation of a common strategy language and communicating it at every level of the organization are almost as important as formulating the strategy itself (Hitachi, 2009, p. 3).

Speculand (2009, pp. 54-55) argues that executing strategy successfully means changing the conversations in the organization. It is estimated that in a weekly management meeting, the team spends 85 percent of its time discussing operations and only 15 percent on strategy and implementation. To be successful in strategy execution strategy this must be reversed.

Kaplan and Norton (2001, p. 319; 2006a, p. 2; 2007, pp. 156 \& 160) are of the view that the leadership in the organization must ensure that meetings deal with the important matters defined in the strategy. The role of effective meetings must not be under estimated as an important element in the successful achievement of the organization's strategy. Meetings must be seen as open and team-based learning processes.

It is evident from the literature review that leaders must be engaged and should lead the execution process from the front. The effective and simplified communication of the strategy is as important as strategy itself. Managers should be "executors" instead of supervisors and should create a culture of sticking to due dates. Management meetings should primarily be used to track and monitor the progress of the execution process and the responsibilities of the role-players must be clear and well understood.

\section{Organization, People, and Skills}

The size and complexity of large organizations forces managers to formulate a well thought through strategy, the conceptual framework assists them to consider resource and market interactions. Well defined business processes assist structures to work. Successful organizations serve more customers, employ more people, and produce more products and services and they expand their environments by introducing new products, expanding into new geographic areas, and using new channels (MacLennan, 2011, p. 15).

Hanley (2007, p. 17) argues that is important to establish a project management office (PMO) with a senior manager in charge to ensure consistency, to track resource allocation, assess progress and to communicate execution updates on a regular basis. The PMO manager is also responsible to standardize planning and reporting templates. 
People are the process owners (individuals and teams) and are accountable to customers and suppliers for the processes they own and should be empowered to effectively improve and amend these processes if the need arises (Pryor et al., 2007, pp. 12-13). Michlitsch (2000, p. 28) argues that strategy execution is best achieved through high-performing people.

Kaplan and Norton (2006a, pp. 2 \& 3; 2007, p. 151; 2001, p. 3) points out that strategy execution requires all business divisions, support units, and employees to be aligned and linked to the strategy. Most organizations and its managers are guilty of 'silo-based' thinking and mal-coordination and conflict. Projects are an effective mechanism for overcoming some of the organizational constraints and have the ability to be run across structural boundaries, bringing together expertise and resources from many disciplines and subunits. Project management is crucial to ensure that critical activities happen (MacLennan, 2011, p. 154).

The launch of a new strategy requires staff members to do things differently. The leader is responsible to identify new skills, knowledge, or attitudes that staff members may need to successfully execute the strategy. In many organizations where execution failed, a common pattern was followed by running a generic organization-wide training program. The leader must identify specific training required and reinforce the training once it has been delivered (Speculand, 2009, p. 31).

Capabilities are important to strategy execution in that the knowledge, skills, and competencies of individuals are vital underpinnings to all organizational actions, strengths, and performance. The ability to take decisions and deliver the right activities in the right way affects everything (MacLennan, 2011, p. 194; Coughlin, 2005 , pp. 4 \& 7). In order to execute a strategy, managers and employees must not only be aware of its existence but must also have the necessary knowledge and skills to execute it.

Sheehan (2010, p. 25) argues that one of the key lessons from the recent recession is that organizations that take on risk without being adequately prepared for these risks will suffer poor performance, and in the worst case become insolvent. If organizations are to survive, and even thrive, in a post-recession world, they must adopt a riskbased approach to the execution of their strategies. The primary benefit of a risk-based approach to strategy execution is that it allows managers to focus on the opportunities outlined in their organization's strategic plans, while at the same time minimize the potential impact of any threats.

It can be concluded that an operating model with well aligned business processes is crucial for the strategy execution process. Organizational restructuring will not automatically lead to improved performance and is not a quick solution. People with the right skills, capabilities, and attitude towards execution are key and even when an organizational structure is not perfect they will perform and deliver what is expected.

\section{Policies, Processes, and Systems}

Policies are directives designed to guide the thinking, decisions, and actions of managers and their subordinates in implementing the organization's strategy. Policies increase managerial effectiveness by standardizing routine decisions and clarifying the discretion managers and subordinates can exercise in executing functional activities. (Pearce \& Robinson, 2011, p. 276).

Pearce and Robinson (2011, pp. 276-277) argues that policies empower people to act and are designed to control decisions while defining allowable discretion within which operational staff can execute business activities by: (1) defining discretion - it controls decisions but empower employees to perform activities without the involvement of top management; (2) promoting the uniform processing of similar activities; (3) ensuring quicker decisions by standardizing answers to previous asked questions; (4) institutionalizing basic aspects of the organization's behaviour; (5) reducing uncertainty in repetitive decision making; (6) counter acting resistance to the chosen strategy of the organization; (7) offering predetermined answers to routine problems; and (8) provides managers with a mechanism to take the right decisions in changing operations.

Control systems, in combination with incentive systems, are important for staff motivation and to ensure appropriate behaviour in relation to the execution process (Heide et al., 2002, p. 219) 
Kaplan and Norton (2006a, p. 13; 2007, pp. $151 \& 154 ; 2001$, p. 3) points out that an organization requires processes and systems that will assist in the effective execution of strategy. Pryor et al. (2007, p. 11) argues that the process owners (i.e., the employees of an organization) must analyze constraints, hierarchical considerations, and environmental impacts that may affect how the process model is applied and the process flows throughout the organization.

A business process is a series of related activities that is repeatedly undertaken to generate a specific output and in an organizational context such outputs could include finished products or services. All organizations use processes which are formed when sequences of activities are repeated to create something. That is not to say that all processes are the right ones or are performed effectively and efficiently. Effective processes are important for strategy execution because some critical activities are ongoing and must be performed repeatedly (MacLennan, 2011, p. 158; Kumar, 2010, p. 319).

It is evident from the literature that policies are important and should be developed with the intention of supporting, streamlining, and simplifying the operations of the organization. The business processes must regularly be reviewed as to ensure that improved performance and services to customers are achieved. Systems and technology should enhance customer processes and provide relevant, accurate and timely management information in the form of dashboards.

\section{Performance Management}

A major obstacle on the road to strategic execution is the inability to accurately measure actual strategic performance. Many organizations focus their measurement efforts on lagging financial outcomes (lag indicators) instead of key drivers of performance (leading indicators). Intangible assets in many instances are typically undervalued or not measured at all (Hitachi, 2009, p. 4).

In many organizations, individual and group incentives are based on a subjective evaluation of performance against goals that may or may not be aligned with the overall strategy. It is estimated that only 25 percent of managers' personal objectives are linked to the organization's strategy. If personal and group targets and incentives are not aligned with the strategy, achieving the desired performance is nearly impossible (Hitachi, 2009, p. 8).

Speculand (2009, pp. 62-63) argues that when leaders launch a new strategy they must create new measures to track the new strategy and stop using the measures that track old strategies. Too many organizations are dependent on financial measures and must develop measures that reflect both tangible and intangible activities. A scorecard allows leaders to translate the strategy into objectives, measures, and actions.

Performance measurement is a very important but complex area to manage. To calibrate and shape the performance of activities and outcomes accurately has many advantages and risks. Managing performance is central to strategy execution. Performance at the individual and team level (even for non-critical activities) is also important to strategy execution (MacLennan, 2011, pp. $136 \& 180$ ).

Performance measures should not be complex but should be relevant, well aligned with the relevant strategic initiatives, and designed to assist the process owners to understand how the process works and where improvements are needed. Measurement is important because it lets the people involved know how well they are doing and how the company is doing at designing and executing changes and achieving their goals and objectives in terms of the set key performance indicators. (Pryor et al., 2007, p. 7).

\section{Resources and Budgeting}

Many organizations fail in strategy implementation because the necessary people capital and financial resources are not provided for in the budget. As a consequence, projects and initiatives get implemented on the cheap, trying to steal time from already busy people manner. This causes many strategies to fail due to inadequate staffing and financial support. Strategy-focused organizations build human and financial resource commitments for strategic initiatives into their organizational plans and budgets (Kaplan \& Norton, 2001, p. 292; Kaplan \& Norton, 2006b, p. 3). 
MacLennan (2011, p. 155) is of the view that organizations must ensure that problems and opportunities that have not been properly assessed do not become projects - consuming time, money, and other resources - without reasonable confidence that these are valid means of achieving strategic objectives. Not all organizations are effective at enabling projects, often failing to timely resource them.

Resources are used to undertake activities and produce outputs and may include people, finances, materials, equipment, information, intellectual property, and other legal rights, no activities can be undertaken without some level of resources. Even the most automated processes must be developed, supervised, and maintained (MacLennan, 2011, p. 165).

An operational budget that enables and resource the execution of projects and activities is crucial. A strategic budget with the objective of reviewing and improving the operating model, systems and business processes is however as important and key to the execution process. Resource allocation could include time, funding, people, equipment and infrastructure.

\section{Services and Customer Care}

Pearce and Robinson (2011, p. 276) make the point that meeting customer needs is a buzzword regularly cited as a key priority by most business organizations. The effectiveness of organizations in meeting their customer needs often fail because the front line are not empowered to make decisions or act to fulfill customer needs. It is important to empower operating staff to make decisions and to use discretion at their level.

The customer perspective is the heart of the strategy and defines how growth will be achieved. The value proposition defines the strategy needed to compete for new customers or increase the share of the existing customers. The customer perspective must be well defined and forms a crucial element in developing a strategy map. Deciding which target group of customers, varieties, and needs the organization should serve is fundamental in developing a strategy (Kaplan \& Norton, 2001, p. 97). The organization exists due to the customers and should be kept at the centre of all actions (Flander, 2010, p. 113).

\section{RESULTS}

\section{Review of Strategy and Planning}

The importance of the "Strategy and Planning" enabler as the first step in the execution process is supported by the legal framework and compliance review as well as the literature review. The "Strategy and Planning" enabler is explained by four (4) factors: (1) "Project Planning"; (2) "Growth and Development Strategy (GDS)"; (3) "Planning, Risk and Compliance"; and (4) "Five (5) Year IDP."

The enabler mean calculated at 2.0 which is an indication that the respondents tended to agree with the statements contained in the "Strategy and Planning" enabler. The enabler seems to be relatively under control.

\section{Review of Leadership and Management}

The results supported the findings in the literature review and confirmed the critical role of leadership and management in ensuring successful strategy execution and the fact that it could be a stumbling block in the strategy execution process if it is not one of the strengths of the municipality. The "Leadership and Management" enabler is in the survey explained by four (4) factors: (1)"General Management"; (2) "Execution Hampering"; (3) "Execution Focus"; and (4) "Management Meetings."

Despite the possible limitation that the respondents were primarily members of the top and middle management, the enabler mean calculated at 2.54 which is an indication that the respondents tended to disagree with the statements, (or agree with the reversed statements), contained in the "Leadership and Management" enabler. 
Areas that require possible attention across the four (4) factors are:

- $\quad$ clear communication of the strategy to all levels of the municipality;

- effectiveness of managers in taking decisions;

- $\quad$ setting an example of sticking to due dates by the senior managers;

- $\quad$ prevention of fraud and corruption;

- $\quad$ inadequate managerial skills and delegated powers;

- coordination across departments and/or municipal entities;

- $\quad$ an over emphasis on compliance instead of execution; and

- the allocation of more time during meetings towards the monitoring of strategy execution.

\section{Review of Organization, People, and Skills}

The results supported the findings in the literature review in terms of the importance of organization, people, and skills in ensuring successful strategy execution and the fact that it could be a barrier if not well resourced and effective. The "Organization, People and Skills" enabler is in the survey explained by five (5) factors: (1) "Human Resource Planning"; (2) "Organizational Structure"; (3) "Morale, Skills Fit and Performance"; (4) "Skills Development"; and (5) "Culture of Execution."

The enabler mean calculated at 2.56 which is an indication that the statements contained in this enabler are viewed by the respondents as evenly balanced between positive and negative.

Areas that possibly require attention across the five (5) factors are:

- $\quad$ inadequate human resources;

- human resource plans;

- $\quad$ skills development plans;

- $\quad$ staff at operational level are not sufficiently skilled;

- the human resource strategy is not aligned and in support of the strategy;

- $\quad$ there is not a clear implementation plan for the human resource strategy;

- $\quad$ talent is not well managed;

- the low morale of employees;

- $\quad$ the inability to fill funded vacancies;

- $\quad$ the absence of a culture that deals decisively with non-performers;

- the existing organizational structure's lack of support to strategy execution;

- $\quad$ the competencies and skills of managers responsible for strategy execution;

- political interference resulting in the best applicants not getting appointed:

- $\quad$ knowledge not well managed;

- $\quad$ investing in management development training;

- $\quad$ investing in project management training;

- $\quad$ creating a culture of continuous innovation; and

- developing a culture of execution urgency.

\section{Review of Systems and Technology}

The results supported the findings in the literature review in terms of the importance of systems and technology in ensuring successful strategy execution and the fact that it could be a barrier if not effective. The "Systems and Technology" enabler is in the survey explained by four (4) factors: (1) "Technology Support"; (2) "Financial System"; (3) "Fleet Management System"; and (4) "Master Systems Plan (MSP").

It is evident from the preceding results that the respondents tended to disagree with the statements contained in the "Systems and Technology" enabler. Possible areas that require attention across the four (4) factors are: 
- $\quad$ the full alignment and integration of information, communication, and technology (ICT) systems;

- the provision of accurate management information;

- the utilization of strategy execution control mechanisms;

- $\quad$ the business processes must support strategy execution;

- $\quad$ procedural manuals for all (ICT) systems;

- $\quad$ an early warning system that monitors high impact service breakdowns;

- a system that monitors time and attendance of staff;

- the utilization of effective billing systems;

- $\quad$ the utilization of technology to monitor fuel consumption;

- the utilization of technology to manage the vehicle fleet;

- $\quad$ an approved master systems plan (MSP) that supports strategy execution; and

- the alignment of the MSP and the core service delivery processes.

\section{Review of Policies, Processes, and Procedures}

The results supported the findings in the literature review in terms of the importance of policies, processes, and procedures in ensuring successful strategy execution and the fact that it could be a barrier if not fully effective.

The "Policies, Processes, and Procedures" enabler is in the survey explained by two (2) factors: (1) "Processes, Procedures, and Governance"; and (2) "Policies." The enabler mean calculated at 2.56 which is an indication that the statements contained in the enabler are viewed by the respondents as evenly balanced between positive and negative. It is evident from the preceding results that the enabler in support of execution is not entirely positive and under control.

Areas that possibly require attention across the two (2) factors are:

- $\quad$ the existing business processes are not effective in delivering services;

- $\quad$ the existing delegated powers do not support the business processes;

- $\quad$ the existing policies do not support speedy decision making;

- $\quad$ the existing policies do not empower the operational managers in implementing projects;

- $\quad$ the development of a policy regulating strategy execution;

- $\quad$ the existing decision making processes are not effective in supporting strategy execution;

- $\quad$ the existing policies are not supported by simplified Standard Operating Procedures (SOPs);

- $\quad$ the review of all policies on an annual basis; and

- $\quad$ the maintaining and regular updating of a policy manual.

\section{Review of Resources and Budgeting}

The results supported the findings in the literature review in terms of the importance of resources and budgeting in ensuring successful strategy execution and the fact that it could be a barrier if not well resourced and fully effective.

The "Resources and Budgeting" enabler is in the survey explained by five (5) factors: (1) "Resources and Project Execution"; (2) 'Annual Spending'; (3) "Under Spending”; (4) "External Resources"; and (5) "SDBIP and Budget Alignment."

The enabler mean calculated at 2.47 which is an indication that the statements contained in this section of the questionnaire are viewed by the respondents as evenly balanced between agree and disagree.

Areas that possibly require attention across the five (5) factors are:

- the resource and strategy alignment;

- $\quad$ the provision of adequate financial resources to achieve the strategy;

- the implementation readiness of capital projects before funding is considered; 
- value for money spending;

- the effective management of external contractors;

- $\quad$ improving the execution of the maintenance budget; and

- improving the execution of the capital budget.

\section{Review of Services and Customer Care}

The results supported the findings in the literature review in terms of services and customer care and as ultimate objective and outcome of successful strategy execution. It also confirmed the findings of the Overview Report (SA, 2009a) that service delivery and customer satisfaction in municipalities are in distress. The "Services and Customer Care" calculated a negative mean of 2.73 (above 2.5). "Services and Customer Care" is in the survey explained by three (3) factors: (1) "Service Standards and Delivery"; (2) "Service Equipment”; and (3) "Customer Relations Management."

The outcome mean calculated at 2.73 which is an indication that the respondents tended to disagree with the statements contained in "Services and Customer Care." Areas that possibly require attention across the three (3) factors are:

- the quality control of services rendered by external contractors;

- minimum service standards were not implemented by a number of municipalities;

- $\quad$ the monitoring of minimum service standard deviations;

- the development of a 5 year maintenance master plan;

- the monthly scheduling of departmental maintenance programs;

- the development and utilization of a customer service delivery index;

- conducting annual customer satisfaction surveys and the utilization of the data to identify the needs and expectations of the customers;

- the identification of key success factors (KSFs) for each service and incorporating it into the planning process;

- the provision of enough vehicles and adequate operational equipment;

- $\quad$ effective Customer Relations Management (CRM) and responding to customer complaints; and

- the answering, within 24 hours, of all received telephone calls and e-mails.

\section{Review of Performance Management}

The results supported the findings in the literature review in terms of the importance of performance management in ensuring successful strategy execution and the fact that it could be a barrier if not well resourced and fully effective.

The "Performance Management" enabler is in the survey explained by two (2) factors: (1) "Performance Monitoring" and Evaluation; and (2) "Productivity and Project Execution."

The enabler mean calculated at 2.68 which is an indication that the respondents tended to slightly disagree with the statements.

It is evident from the preceding results that the enabler in support of execution is not entirely positive and under control and areas that require attention across the two factors are:

- the effectiveness and fairness of the Performance Management System (PMS);

- the matching of the goals and reward system of the municipality;

- the official performance measuring of the operational work teams;

- the utilization of an operations planning and execution centre;

- the regular measuring of productivity and the implementation of a productivity improvement program;

- the capturing of all projects in the form of project charters;

- the weekly monitoring and evaluation of the execution progress of projects; 
- $\quad$ the implementation of a standardized and simplified one-page project progress report;

- $\quad$ the roll out of the Performance Management System (PMS) to all staff levels; and

- the common understanding of the municipality's priorities by all employees.

It is important to note that the results further confirm the general perception that the community will respond negatively to the municipality's effectiveness in delivering the expected services (mean of 2.82).

\section{DISCUSSION}

The empirical results confirmed that the seven (7) key enablers identified in the literature review, are all applicable and relevant to the strategy execution process in municipalities. The actual results, ideal results, and the centre point of the results are reported in Figure 1.

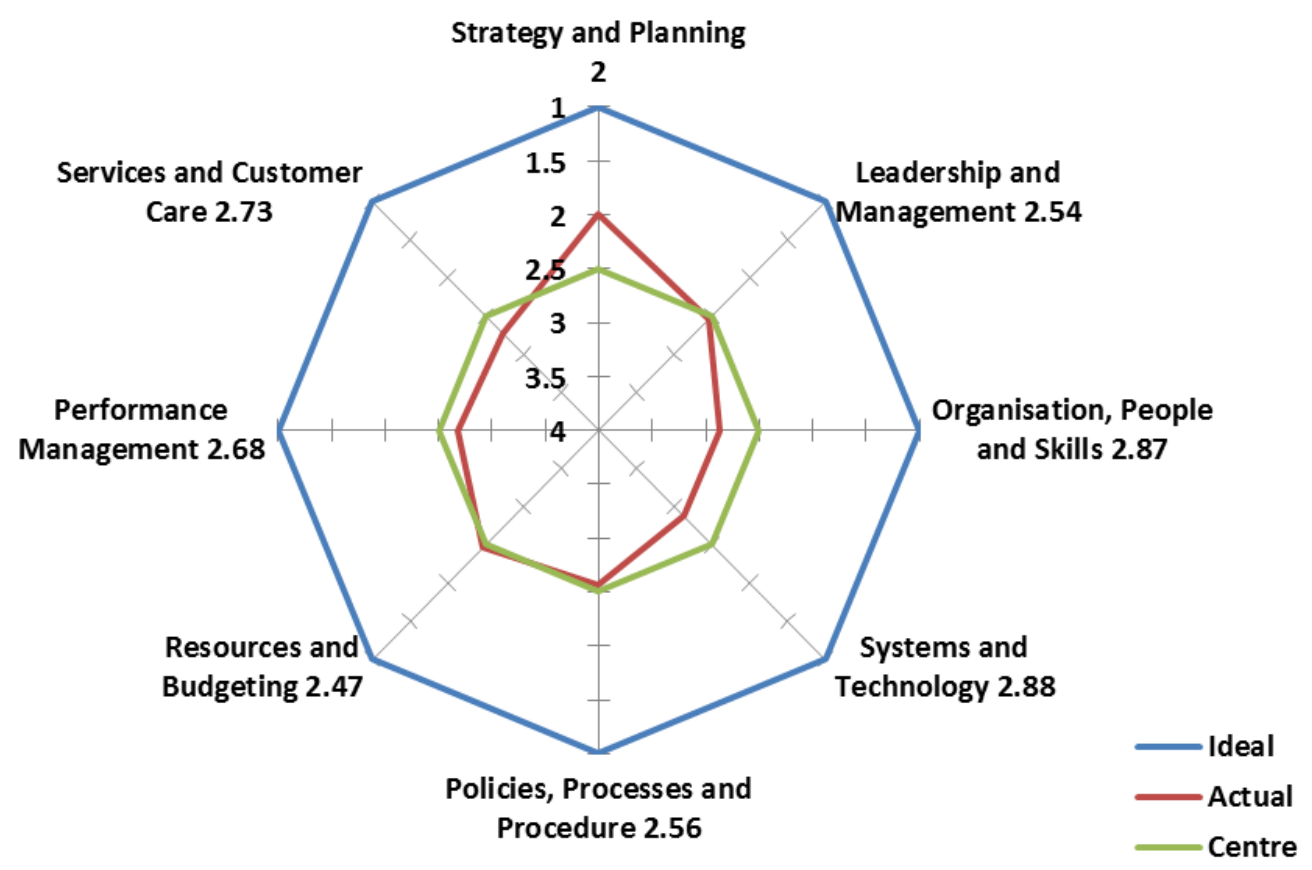

Figure 1: Strategy Execution Enablers

The following conclusions are drawn from the research:

These enablers were identified as part of the literature review and derive from various concepts, theories, and the strategy execution frameworks. 


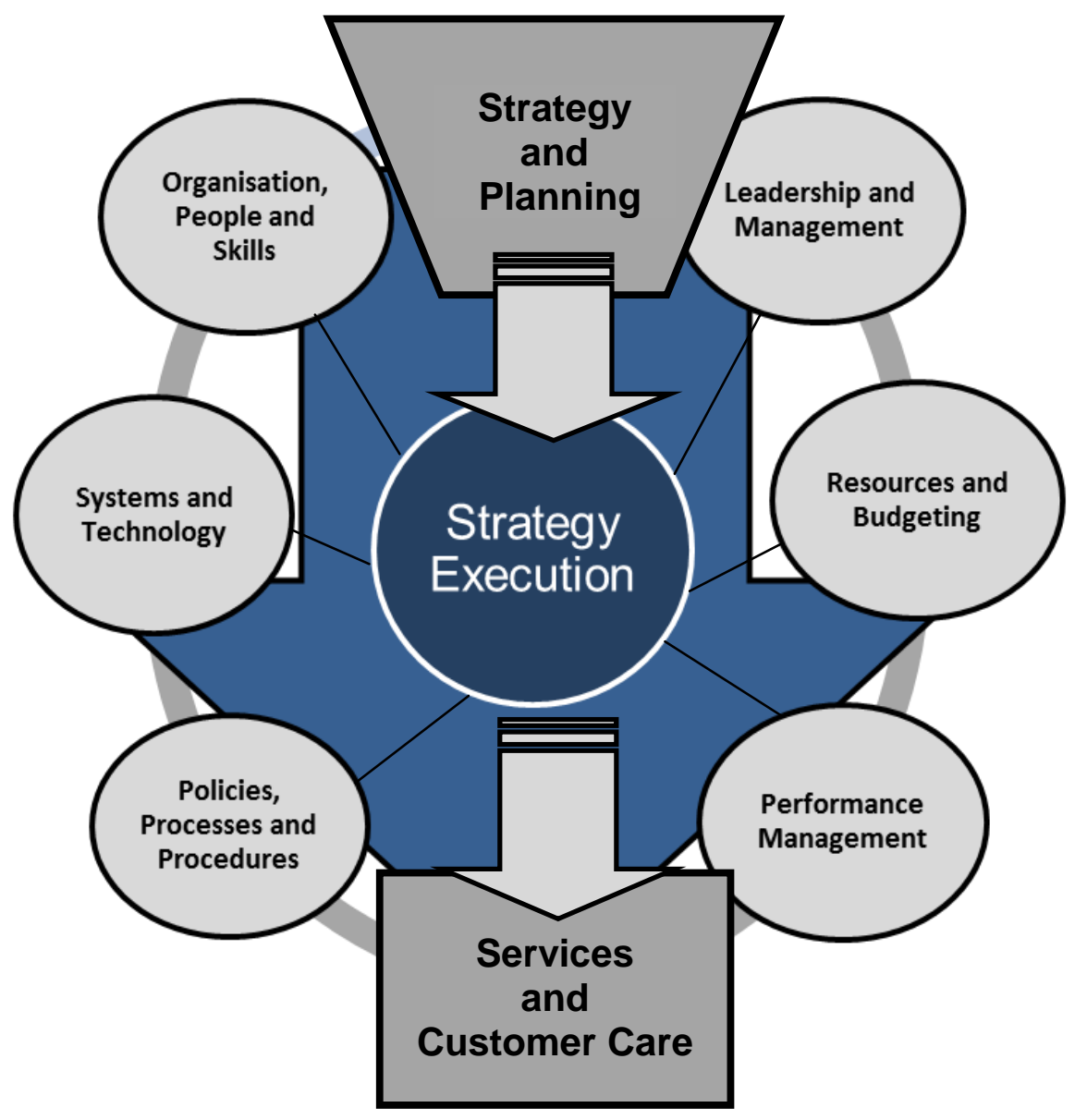

Figure 2: An Integrated Operating Framework for Strategy Execution in Local Government

By developing this framework the research contributes to a better understanding of the enablers that may have an effect on the ability of municipalities to execute its strategies. The identified enablers and the integrated operating framework for strategy execution suggest important insights for managers and researchers and create the opportunity for future research, which will form part of the recommendations.

The developed integrated operating framework is based on the principle that "Strategy and Planning" sets the scene and is the starting point in the execution process and the ultimate outcome and success of the execution process will be measured in terms of "Services and Customer Care."

\section{CONCLUSION}

The ultimate strategy execution outcome of a municipality is "Services and Customer Care." The literature research identified seven (7) key enablers required for successful strategy execution: (1) "Strategy and Planning"; (2) "Leadership and Management"; (3) "Organization, People and Skills"; (4) "Systems and Technology"; (5) "Policies, Processes and Procedures"; and (6) "Resources and Budgeting"; (7) "Performance Management."

The literature research confirmed that municipalities in South Africa is well regulated, almost over regulated, with regards to the three (3) enablers: "Strategy and Planning"; "Resources and Budgeting"; "Performance Management"; as well as the ultimate strategy execution outcome and objective of local government: "Services and Customer Care." 
Four (4) key enablers which are not specifically or well regulated in terms of legislation and regulations are: (1) "Leadership and Management"; (2) "Organization, People and Skills"; (3) "Systems and Technology"; and (4) "Policies, Processes and Procedures." It is recommended that clear guidelines be developed to guide and regulate these crucial enablers.

The "Strategy and Planning" enabler in municipalities is well regulated and determines the roadmap for municipalities towards achieving the desired objectives and ultimately "Services and Customer Care." It is evident from the empirical results in Figure 1 that none of the enablers calculated results close to the ideal. The "Strategy and Planning" enabler however calculated the highest result.

"Services and Customer Care" constitute the ultimate objective and outcome of the municipal strategy execution process and it is one of the areas in local government which is well regulated. The results as reported in Figure 2 below confirm the findings of the Overview report (SA, 2009a) and indicate that the respondents tended to disagree that service delivery and customer care is under control.

The results further confirmed that the respondents tended to disagree with the very important statement that: "the community will rate the municipality as effective in delivering the expected services" which is confirmation that the municipalities are not effective in executing their strategies and plans.

All the factors of the "Strategy and Planning" enabler calculated results above the centre point and it appears that "Project Planning"; the "Growth and Development Strategy (GDS)"; and "Planning, Risk, and Compliance" is relatively under control. The results of the "Five (5) Year Integrated Development Plan (IDP)" recorded the highest results and it is clear that the municipalities are complying with the legal requirements regulating IDPs.

The "Leadership and Management" enabler is important and critical in ensuring successful strategy execution. According to the empirical results leadership and management is an area that requires attention.

The human capital of a municipality is arguably the most important resource and enabler. The “Organization, People, and Skills" enabler is critical for successful strategy execution in a municipality.

The "Systems and Technology" enabler is also important to ensure successful execution of the municipality's strategy.

The results of the "Policies, Processes, and Procedures" enabler reported confirm that it is not viewed by the respondents as entirely positive and under control is also an area that requires attention.

The "Resources and Budgeting" enabler is also well regulated. According to the results it recorded the second highest result and whilst it is not entirely positive and under control, the respondents viewed it as more positive than the other enablers.

Performance Management is a very crucial element in the execution process. It is supposed to produce the accurate and credible performance results and dash boards of how well or poor the municipality's performance and execution is. Whilst the "Performance Management" enabler is well regulated the results however indicate that the respondents are not that positive and this is an area of concern that requires attention.

\section{RECOMMENDATIONS}

The seven (7) identified key enablers will form the key pillars of the developed integrated operating framework for strategy execution.

Based on the empirical results it is recommended that municipalities implement the corrective measures as proposed. Some of the corrective measures include addressing and/or implementing: 
- $\quad$ minimum service standards;

- $\quad$ customer relationship management;

- $\quad$ customer satisfaction surveys; and

- $\quad$ equipment required to render services.

Based on the empirical results it is recommended that municipalities monitor and review the execution process regularly and preferably at least twice a month. It is also recommended that due to the importance of a credible strategy that further and future empirical research should investigate the content and quality of the strategies developed by municipalities.

Some of the key leadership and management issues to address are:

- $\quad$ productive meetings focusing on the monitoring and tracking of execution;

- $\quad$ effective decision making and sticking to due dates;

- $\quad$ the prevention of fraud and corruption;

- $\quad$ clear and simplified communication of the strategy;

- $\quad$ improved managerial and project management skills; and

- $\quad$ delegated powers that support effective strategy execution.

Some of the key organization, people, and skills issues to address are:

- $\quad$ human resource planning;

- $\quad$ organizational structure;

- $\quad$ morale, skills fit and performance;

- $\quad$ skills development; and

- $\quad$ culture of execution and sense of urgency.

Some of the key systems and technology issues to address are:

- $\quad$ the development of a Master Systems plan (MSP);

- $\quad$ provision of accurate management information;

- $\quad$ systems to support the operations such as fleet management, finance, and billing;

- $\quad$ an early warning system for high impact service breakdowns; and

- $\quad$ the full alignment and integration of information, communication and technology (ICT) systems.

It is also recommended that due to the importance of effective and functional business processes and procedures that further and future empirical research should investigate the state and effectiveness thereof in municipalities. Some of the key policies, processes, and procedures issues to address are:

- the regular review of policies in terms of its relevancy and support to the execution process;

- $\quad$ the review and alignment of delegated authority;

- $\quad$ the review of decision making processes in support of effective execution; and

- $\quad$ the development of simplified Standard Operating Procedures (SOPs).

Some of the key resources and budgeting issues to address are:

- $\quad$ the alignment of resources and the strategy;

- $\quad$ the provision of adequate financial and other resources;

- $\quad$ value for money spending;

- $\quad$ the effective management of external contractors; and

- $\quad$ improving the maintenance and capital budget spending. 
Some of the key performance management issues to address are:

- $\quad$ the regular monitoring and improvement of productivity;

- $\quad$ the capturing of all projects in project charters;

- $\quad$ the roll out of the Performance Management system (PMS) to all levels;

- $\quad$ the weekly monitoring and evaluation of the execution process;

- $\quad$ establishing a planning and execution monitoring centre (room); and

- $\quad$ the common understanding of the objectives and priorities by all employees.

\section{ACKNOWLEDGEMENT}

This research stems from research done by JH Leibbrandt as part of his Phd studies at North West University, Potchefstroom Business School

\section{AUTHOR INFORMATION}

Johannes Leibbrandt was awarded his Phd degree in Business Administration from the North West University in 2013. He acted as the CEO of the Kempton Park/Tembisa Metropolitan Council and serves in this position from 1989 - 2002. He then became the Deputy City Manager of Ekurhuleni Metropolitan Council and stayed in this position from 2002- 2010. He is currently employed as Director of PriceWaterhouseCoopers (PWC). He serves currently in Kenia in Africa where he manage and develop the international interest of PriceWaterhouseCoopers (PWC). E-mail: johan.leibbrandt@za.pwc.com

Christoff Botha was awarded his PhD degree in Industrial Sociology from the Potchefstroom University for Christian Higher Education. He is a Chartered Human Resource Practitioner and registered with the South African Board of Personnel Practitioners. He also specialises in gender studies and woman in mining. Apart from research and writing he also practices Employment Relations on a part time basis for more than 20 years. He is currently in the position of Associate Professor at the North West University, Potchefstroom Business School in South Africa. Email: Christoff.botha@nwu.ac.za (Corresponding author)

\section{REFERENCES}

1. Beer, M., \& Eisenstat, R. A. (2000). The silent killers of strategy Implementation and learning. Sloan Management Review, 41(4), 29-40.

2. Bossidy, L., Charan, R., \& Burck, C. (2002). Execution: The discipline of getting things done. London: Crown Business.

3. Brenes, E. R., Mena, M., \& Molina, G. E. (2008). Key success factors for strategy implementation in Latin America. Science Direct, 61, 590-598.

4. Constitution see South Africa. (1996).

5. Coughlin, D. (2005). Strategy, planning and execution: How to establish an effective strategy and execute successfully within it. A Special Report on Business Acceleration.

6. De Flander, J. (2010). Strategy execution herous: Business strategy implementation and strategic management demystified. Brussels: Performance Factory.

7. Hanley, C. A. (2007). The execution challenge: Translating strategy into action Bank accounting and finance, 17-20, Oct-Nov.

8. Heide, M., Grønhaug, K., \& Johannessen, S. (2002). Exploring barriers to the successful implementation of a formulated strategy. Scandinavian Journal of Management, 18, 217.231.

9. Hrebiniak, L. G. (2005). Making strategy work: Leading effective execution and change. Upper saddle River, NJ: Wharton School Publishing.

10. Hrebiniak, L. (2008). Making strategy work: overcoming the obstacles to effective execution. Ivey Business Journal, Mar/Apr.

11. Jooste, C., \& Fourie, B. (2009). The role of strategic leadership in effective strategy implementation: Perceptions of South African strategic leaders. South African Business Review, 13(3), 51-68. 
12. Kaplan, R. S., \& Norton, D. P. (2001). The strategy-focused organization. USA: Harvard Business School Publishing Corporation.

13. Kaplan, R. S., \& Norton, D. P. (2006a). How to implement a new strategy without disrupting your organization. Harvard Business Review, 1-10.

14. Kaplan, R. S., \& Norton, D. P. (2006b). Why system, not structure, is the way toward strategic alignment: A historic perspective. Balanced Scorecard Report, 8(4), 1-16.

15. Kaplan, R. S., \& Norton, D. P. (2007). Using the balanced scorecard as a strategic management system. Harvard Business Review, 150-160.

16. Kumar, D. (2010). Enterprise growth strategy. Surrey: Gower Publishing Limited.

17. Maclennan, A. (2011). Strategy execution: Translating strategy into action in complex organizations. New York: Routledge.

18. Michlitsch, J. F. (2000). High-performing, loyal employees: The real way to implement strategy. Strategy and Leadership, 28(6), 28-34.

19. Miller, S., Wilson, D., \& Hickson, D. (2004). Beyond planning: Strategies for successfully implementing strategic decisions. Long Range Planning, 37, 201-218.

20. Municipal Finance Management Act see South Africa. (2003).

21. Municipal Structures Act see South Africa. (1998b).

22. Municipal Systems Act see South Africa. (2000a).

23. Nielson, G. L., Martin K. L., \& Powers E. (2008). The secrets to successful strategy execution. Harvard Business Review, 61-70.

24. Pearce, J. A., \& Robinson, R. B. (2011). Strategic management: Formulation, implementation and control. New York: Mc Graw-Hill/Irwin.

25. Pietersen, J., \& Maree, J. G. (2007). Standardisation of a questionnaire. In J. G. Maree (ed.), First steps in research. Pretoria: Van Schaik.

26. Pryor, M. G., Anderson, D., Toombs, L. A., \& Humphreys, J. H. (2007). Strategic implementation as a core competency: The 5Ps model. Journal of Management Research, 7(1), 51-68.

27. $\quad$ Raps, A. (2004). Implementing strategy. Strategic Finance, June, 49-53.

28. Salkind, J. (2007). Exploring research (6th ed.). Uppersaddle River, N.J.: Pearson.

29. Schaap, J. I. (2006). Toward strategy implementation success: An empirical study of the role senior - level leaders in the Nevada Gaming Industry. Gaming Research and Review Journal, 10(2), 13-29.

30. Sheehan, N. T. (2010). A risk-based approach to strategy execution. Journal of Business Strategy, 32(5), 25-37.

31. South Africa (SA). (1996). Constitution of the Republic of South Africa, Act 108, as adopted by the Constitutional Assembly on 8 May 1996 and as amended on 11 October 1996. Pretoria: State Press.

32. South Africa (SA). (1997). White Paper on Transforming Public Service Delivery: Batho Pele - 'People First'. Pretoria: State Press.

33. South Africa (SA). (1998a). White Paper on Local Government. Pretoria: State Press.

34. South Africa (SA). (1998b). Municipal Structures Act, 117 of 1998. Pretoria: State Press.

35. South Africa (SA). (2000a). Municipal Systems Act, 32 of 2000 and as amended in 2005. Pretoria: State Press.

36. South Africa (SA). (2000b). Department for Cooperative Governance and Traditional Affairs: IDP guide pack: Guide 0. Cape Town: Formeset Printers Cape (pty) limited.

37. South Africa (SA). (2000c). Department for Cooperative Governance: IDP guide pack: Guide 1. Cape Town: Formeset Printers Cape (pty) limited.

38. South Africa (SA). (2000d). Department for Cooperative Governance: IDP guide pack: Guide II. Cape Town: Formeset Printers Cape (pty) limited.

39. South Africa (SA). (2000e). Department for Cooperative Governance: IDP guide pack: Guide III. Cape Town: Formeset Printers Cape (pty) limited.

40. South Africa (SA). (2001). Department for Cooperative Governance and Traditional Affairs: Municipal planning and performance regulations. Pretoria: State Press.

41. South Africa (SA). (2003). Municipal Finance Management Act, 56 of 2003. Pretoria: State Press.

42. South Africa (SA). (2005). National Treasury: Municipal Finance Management Act. Circular 13.

43. South Africa (SA). (2006a). National Treasury: A guide to municipal finance management for councilors. 
44. South Africa (SA). (2006b). Department of Cooperative Governance: Local Government: Municipal performance management regulations for municipal managers and managers directly accountable to the municipal managers. Pretoria: State Press.

45. South Africa (SA). (2009a). Department for Cooperative Governance: State of Local Government in South Africa: Overview Report. Pretoria: State Press.

46. South Africa (SA). (2009b). Cabinet decision: Local government turnaround strategy (LGTAS). Retrieved 15 Jan. 2011 from http://lgict.org.za/document/local-government-turnaround-strategy-lgtas-2009

47. South African Local Government Association (SALGA). (2001). Integrated development planning: A practical guide to municipalities.

48. South African Local Government Association (SALGA). (2011). A handbook for municipal councillors: Councillor induction.

49. Speculand, R. (2009). Beyond strategy: The leader's role in successful implementation. USA: Jossey-Bass.

50. Spinosa, C. (2008). Effective executive. Interview, 21-31, Sep.

51. Wheelen, T. L., \& Hunger, J. D. (2004). Strategic management and business policy (ninth ed.). Englewood Cliffs. NJ: Prentice Hall. 
NOTES 